\title{
Research of Financial Management System Based on Intelligent Age
}

\author{
Fuping Zhou, Yazhen Zhang, Minying Fang, Jinshou Zhang \\ Guangzhou College of Technology and Business, Guangdong, China
}

Keywords: financial management system, web services, architecture

\begin{abstract}
With the global economy increasingly integrated, enterprises have met with a lot of problems in the course of financial management informatization. This paper put forward a method, which is done by means of Web Services technologies, to work out financial management integration and finance working in collaboration with business. The paper firstly analyze existing problems, and simply introduce Web Services technologies, lastly discuss architecture of system and functionalities of system and other key issues which need to be solved. The project builds a enterprise application model based on Web Services, which fully uses Internet technologies and Web Services technologies, and implements financial management and accounting computing informatization using $\mathrm{B} / \mathrm{S}$ model.
\end{abstract}

\section{Introduction}

With the deepening of economic globalization, business survival environment has undergone profound changes and industry relationships shift from competition to cooperation between upstream and downstream businesses and enterprise operation pattern of traditional products as core changes to customer - oriented. Enterprises to adapt to this change needs to optimize their economic and organizational structure, which in turn rises "collaborative commerce, centralized management, real time processing" information needs. In the financial management of enterprise information in China Problems in the process of, mainly: (1) poor financial data analysis of timeliness in a timely manner. Enterprise financial data " Island of the " business processing system data cannot flow into the financial system, not a seamless join, have barriers on the real - time enterprise accounting financial analysis, cause analysis functionality is not strong, delay analysis of financial reporting.(2) centralized financial management not enough. Companies use financial software for business support, centralized financial management in difficult to reach. Unable to establish effective under the overall context of the budget system, lack of planning and budgeting in advance, there is a lack of real - time monitoring, audit and supervision are also a formality after, difficulties and risks for financial management.

\section{Study on Technology}

Web services based on interoperable distributed application on the new platform, is a standard application is defined in a Web environment to achieve interoperability, for on the Internet or intranet by using a standard XML protocols and message formats to implement business applications services.

Web services architecture. Web services architecture is service - oriented architecture (SOA).You can see from Fig. 1, there are three roles in the SOA structure:

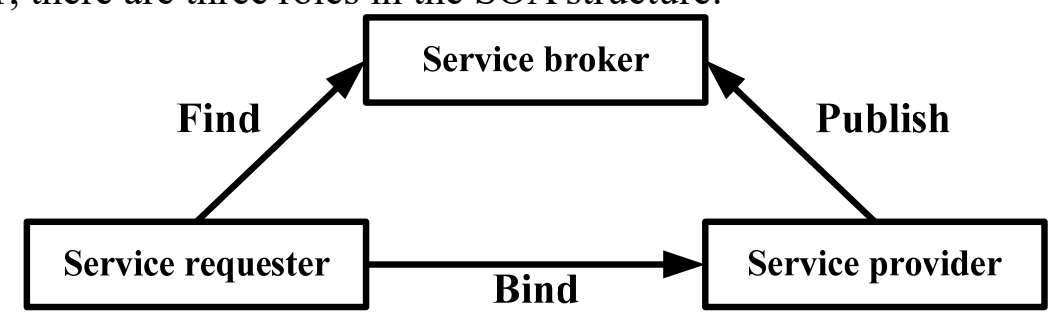

Fig.1 Web services architecture 
(1) Service Provider ( service providers ) : Provide services and publishing services information by registering.

(2) Service Broker ( Service agent ) : Publishing and location of provision of services, typically UDDI.

(3) Service requester ( service requester ) : Through the service agent queries the service, and binding services provided through the service.

\section{Application Integration Based on Web Service Technology.}

Web services is to create a new platform for distributed applications interoperable, the main target is a cross-platform interoperability.In order to achieve this goal, the Web service is based entirely on XML, XSD, and other platform - independent software vendor - independent standards ; and applications to communicate across platforms and across the network is very useful when, for application integration, business-to-business integration, reuse of code and data, as well as client and server communicate through a Web forum.

\section{Architecture of Financial Information System}

Financial Management Information System Based on Web services, in common other than the accounting bookkeeping process provided in the form of web services, special offers connections to other business with standard interfaces of the subsystem ; the son of business System ( such as salary system ), business generated data real - time financial data. System architecture as shown in Fig.2.

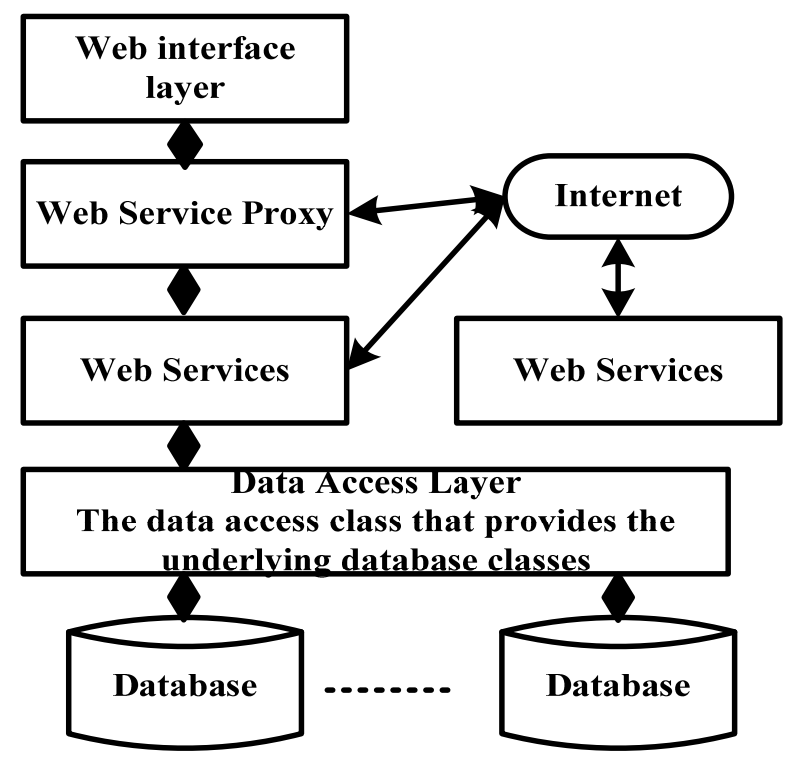

Fig.2 Information System Architecture

Database systems required to store information such as data and stored procedures that perform database operations. The data access layer provides database access interface classes for the database. This class provides connection, close, and the functionality of your database. Web services provide access to the business logic processing interface. It services can call a method on a data access layer encapsulates the business logic of the system to provide services to the web interface, or through other public services already exists on the Internet called the Internet.. Net through WSDL. Exe or ASP. Net tools to create a Web service proxy class in the client code creates an instance of a Web service proxy class, by calling the instance method of the proxy class communicates with the Web service method. 


\section{Function Analysis of Financial Information System}

\subsection{The functionality of the system structure.}

Financial Management Information System Based on Web services in Visual Studio.Net development tools as the foreground, with large databases Microsoft SQL server2000 as a data management tool, combining the features of the Web services development. Its features include : voucher processing, report management, financial analysis, wage accounting, Statement of Cash Flows, data query module, as shown in Fig. 3 ; it covers enterprise accounting in public institutions required for basic functionality for all sectors of the financial management needs.

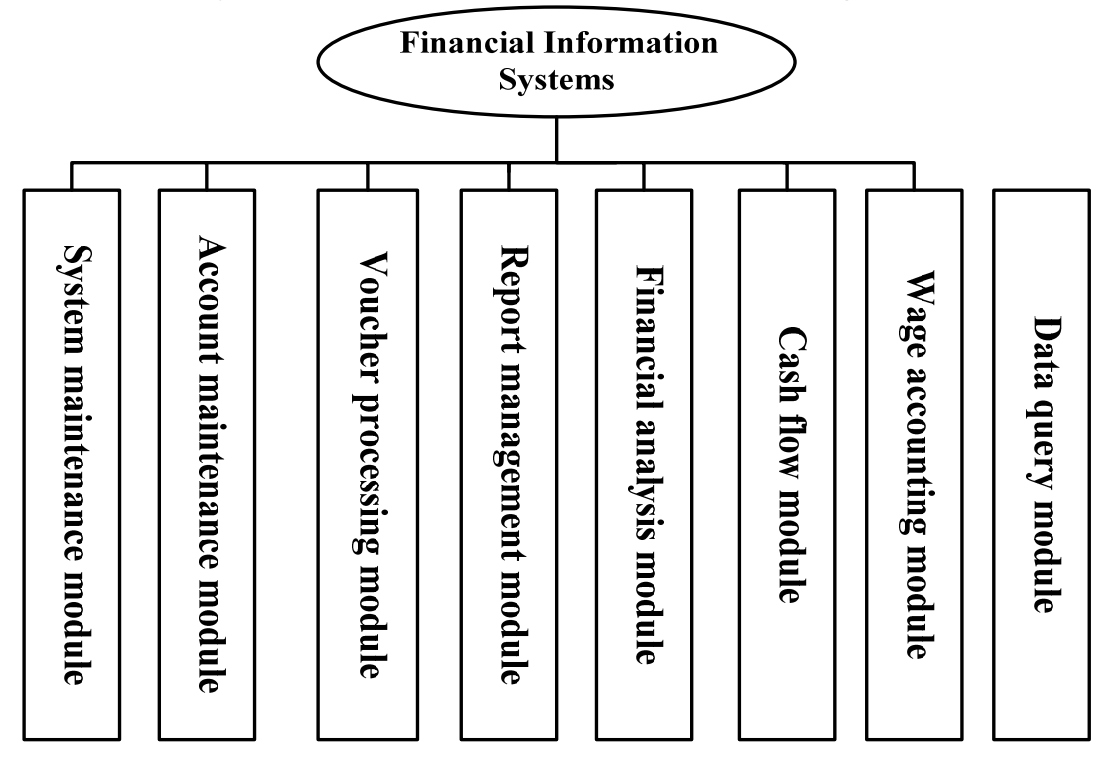

Fig.3 System function chart

\subsection{Data access layer.}

Primarily responsible for the data access layer and close connections to the database and interact with the data from the database ; Use stored procedures to obtain data, and can use ADO.Net send data to the database, returns the database operation or a query result. The data access layer in the software system is as sjcw.Sln solution file in the data access project implementation. Traditional accounting model system for the use of modern information technology is fully integrated, and integration on the basis of the information technology, computer and network technology and accounting degree of integration, the formation of an open modern financial accounting information systems.

In other words, the design and application of the system, reflects a process of financial data and information technology convergence, the process is the most original of the financial information as an information resource management, full implementation of the use of computer, networking and communications Based information technology, most of the initial resource extraction, storage, a comprehensive, in-depth treatment delivery, processing, application, etc., for the school management, control and decision-making, as well as social and economic operation to provide true, comprehensive and timely information.

\subsubsection{Web services layer.}

Software system of Web services layer is composed of a set of core services. Web services layer is responsible for receiving web interface - level data request, the necessary business logic checks them (including permission checking, and so on ), then the request is broken down into different database operations are processed by the data access layer calls the appropriate method, and returns the result to interface layer. Web services are built on. On the NET Framework and the common language runtime, all the business component services based on different modules divided into different packages, isolation module through this division, avoiding interactions between modules, 
as well as ease of implementation.

\subsubsection{Web interface layer.}

Main role is to receive user interface layers of instructions or data input, the legality of the data and parity; verify the contents of the data value of the form and scope, if the data is not legitimate, prompt in the client process and legally submit data to the business logic layer for processing, and is responsible for the business logic layer processing of results displayed to the user. Part of the data validity checks on the client, avoiding illegal to transfer the data to server authentication, reduces network traffic, thereby reducing the load on the server.

\subsubsection{Safety design of software system.}

Financial Management Information System Based on Web services support multiple levels of security controls, security clearance requirements of the corresponding financial system so that the public financial system - level information can be shared effectively in a business network, and corresponding secret, secret and top secret classification level to provide appropriate countermeasures. We need to use advanced information technologies and means, networks, breaking the bottleneck of all kinds suited to modern high-speed development, the initiative to provide financial services to continuously improve efficiency and improved ways of working to provide more kinds of information necessary for the leadership to assist leadership decision-making, to provide more high-quality financial information services.

\section{Summary}

Web services provide a distributed application integration, and platform - independent mechanisms, make the system design can be done in a more flexible way. Currently, the Web service is widely used in applications there are still many problems, such as how to effectively protect the security of the Web service because of limited by Internet bandwidth, Web services transfer of large amounts of information do not receive a timely response, limit the scope of its use; in addition, the enterprise reconstruction of existing applications even for the Web service is a painstaking job. However, service - oriented programming ideas, represent the next generation.

\section{Acknowledgements}

2017 Guangzhou College of Technology and Business Textbook Project 'The Information System of Accounting' (2017JC-08) ; 2017 Guangzhou College of Technology and Business Quality Engineering Project 'Managerial \& Accounting Talent Pattern Research based on Big Accounting Perspective' (ZL20171101) ; 2017 Guangzhou College of Technology and Business Quality Engineering Project 'Undergraduate Academic Staff Development Project on Accounting (Financial Management)' (ZL20171145); 2017 Guangzhou College of Technology and Business Quality Engineering Project 'Off-Campus Academic Practice Base on Accounting of GCTB' (ZL20171146)

\section{References}

[1] Galloway, Phil Haack, Brad Wilson, K. Scott Allen: Professional ASP.NET MVC 4 (Wrox Press, USA 2012).

[2] C. Wang, P. Zhang: ASP. net/xml in-depth programming technology(Beijing hopes the electronic press, China 2011).

[3] Chai Xiaolu, and Liang yuqi: The Web services technology, Schema, Applications (Electronics Industry Press, China 2007)

[4] Information on http://techng. onlinechina.net/content.asp.titleid=690. 